\title{
TEACHING ENGLISH GRAMMAR TO HIGH SCHOOL STUDENTS: COGNITIVE APPROACH
}

\section{Liudmyla Naumenko}

Department of Teaching Methodology of Ukrainian and Foreign Languages and Literatures, Institute of Philology, Taras Shevchenko National University of Kyiv, Ukraine

Yana Bilyk

Institute of Philology, Taras Shevchenko National University of Kyiv, Ukraine

Abstract

Background: Cognitive approach to teaching foreign languages at high school proves rather effective given the level of intellectual development and interests of learners in their early youth. The approach, based on conscious learning, currently finds support in the documents on school reform being conducted in Ukraine.

Purpose: The purpose of the article is to discuss provisions of cognitive approach to teaching a foreign language at high school and establish correlation between logical operations of thinking and types of syntactic exercises in the process of learning grammar.

Discussion: Teaching grammar is a challenging task, especially if combined with the basic vocabulary taught parallelly. However, cognitively and thematically oriented exercises facilitate the learning process, making it more sensible and smoother. Cognitive grammar exercises also meet the learners' expectations and develop their intellectual abilities, deepen memory, train attention and logical thinking. Besides developing their grammatical and lexical skills, the students acquire cognitive abilities to make a choice, find out necessary answers, solve problems, etc., which can be exceptionally useful in everyday life and professional setting. The proposed grammar exercises which are classified according to their types into multiple choice, transformation, comparing, grouping, logical thinking, formulation of definitions and language games can be further completed with different variations which will add additional quest to the learners.

Results: The latest achievements of cognitive linguistics and cognitive psychology have a powerful impact on the development of new methods and approaches to language teaching. Cognitive approach to teaching foreign languages proves to be one of the most effective instruments of teaching-learning process, especially based on the knowledge of psycho-physiological development of the object of study.

Key words: cognitive approach, language pedagogy, Active / Passive voice.

\section{Vitae}

Liudmyla Naumenko, Dr.Sc., Associate.Professor, Department for Teaching Methodology of Ukrainian and Foreign Languages and Literatures. Areas of research interests: cognitive linguistics, discourse analysis, business English, methodology of teaching English.

Correspondence: I.naumenko@knu.ua

Yana Bilyk, MA in Education, specialization: «Ukrainian and foreign philology: theory and methodology of teaching». Areas of research interests: methodology of teaching Ukrainian and foreign languages.

Correspondence: yadikhnych@gmail.com

УДК 378.091.33-0.28.23:811.111

ORCID: 0000-0002-1398-9554

НАТАЛІЯ ЛУТКОВСЬКА (м. КИїв)

\section{КРИТЕРІЇ ОЦІНЮВАННЯ РІВНЯ ІНШОМОВНОЇ КОМУНІКАТИВНОЇ КОМПЕТЕНТНОСТІ СТУДЕНТІВ ЕКОНОМІЧНИХ СПЕЦІАЛЬНОСТЕЙ У МОНОЛОГІЧНОМУ МОВЛЕННІ, СФОРМОВАНОÏ НА ЗАСАДАХ АУДІОВІЗУАЛЬНОЇ ІМПЛІЦИТНОЇ ПРОФЕСІЙНОЇ ОРІЄНТАЦІЇ}

Статтю присвячено питанням оцінювання іншомовної комунікативної компетентності студентів економічних спеціальностей на початковому етапі навчання. Визначено критерії оцінювання рівня іншомовної комунікативної компетентності у монологічному мовленні, сформованої на засадах аудіовізуальної імпліцитної професійної орієнтації. Представлено зразки завдань зрізів комплексного контролю рівня сформованості іншомовної соціокультурної і профресійно орієнтованої комунікативної компетентності у монологічному мовленні студентів економічних спеціальностей на I курсі з прикладами оцінювання мовленнєвого продукту за визначеними критеріями.

Ключові слова: аудіовізуальна імпліцитна профресійна орієнтація, відеофронограма, іншомовна соціокультурна і профресійно орієнтована комунікативна компетентність, критерії оцінювання, монологічне мовлення, соціокультурно й економічно марковані лексичні одиниці, студенти економічних спеціальностей.

Постановка проблеми та актуальність дослідження. Програма з англійської мови для профресійного спілкування передбачає оволодін- ня іноземною мовою через фрормування іншомовної професійно орієнтованої комунікативної компетентності («Programa»). У сучасній мето- 
дичній науці і практиці викладання іноземних мов студентам немовних спеціальностей на початковому етапі навчання спостерігаються 4 тенденції: 1) формування соціокультурного компоненту в непрофесійних сфрерах комунікації окремо на початковому етапі з наступним формуванням компоненту професійної орієнтації у професійних сорерах спілкування; 2) формування професійної орієнтації в професійних сферах комунікації; 3) формування професійної орієнтації паралельно з наданням студентам фахових знань; 4) поєднання формування на початковому етапі соціокультурного компоненту і професійної орієнтації у тісному взаємозв'язку в непрофесійних сферах комунікації. Найбільш доцільним є інтеграційне формування соціокультурної і професійно орієнтованої комунікативної компетентності, тому що професійно орієнтоване навчання пов'язане із залученням до навчального процесу сорормованих у процесі навчання фаху рідною мовою професійних знань, навичок і вмінь. Студенти I курсу мають певні очікування щодо зв'язків іноземної мови зі спеціальністю, проте вони тільки починають вивчати фах рідною мовою й ще не володіють іноземною мовою на такому рівні, щоб ефективно спілкуватися у професійних сфрерах комунікації. Тенденцію інтеграційного формування соціокультурної і професійно орієнтованої комунікативної компетентності - імпліцитну професіоналізацію - представлено у дисертаційному дослідженні Е.В. Мірошніченко (Miroshnichenko). Сутність імпліцитної професіоналізації полягає в інтегрованому засвоєнні студентами загальновживаної лексики і частини професійно маркованих лексичних одиниць (ЛО) на початковому етапі навчання. Проте таку методику створено для використання друкованих текстів з урахуванням графічних образів професійно маркованих ЛО. На відміну від Е.В. Мірошніченко, ми пропонуємо аудіовізуальну імпліцитну професійну орієнтацію - інтеграційне формування соціокультурної і професійно орієнтованої комунікативної компетентності студентів економічних спеціальностей у монологічному мовленні з використанням автентичної відеофонограми з урахуванням аудитивних образів професійно маркованої лексики.

Короткий огляд публікацій 3 теми. Як свідчить аналіз методичних досліджень, набір критеріїв оцінювання сорормованості іншомовної комунікативної компетентності у монологічному мовленні залежить від теоретичних засад навчання і специфіки розроблених дослідниками методик. Основні науково обґрунтовані критерії оцінювання вмінь усного мовлення виокремлено у працях В.Л. Скалкіна, Ю.І. Пассова, Н.К. Скляренко. Вони визначаються психологічними (односпрямованість, зв'язність, тематичність, відносно безперервний спосіб мовлення, логічна послідовність) і лінгвістичними (структурна завершеність речень, відносна повнота висловлювань, розгорнутість і різноструктурність фраз) характеристиками монологу. До основних критеріїв належать: відповідність висловлювання комунікативному наміру, відносна правильність мовлення, зв'язність, темп мовлення, обсяг висловлювання. У методичній літературі описано чимало праць, присвячених оцінюванню іншомовної комунікативної компетентності у монологічному мовленні студентів мовних і немовних спеціальностей, сформованої на основі як друкованих, так і аудіовізуальних матеріалів (Asadchykh, Fedorova, Kirzhner, Liamzina). Проте питання оцінювання рівня іншомовної комунікативної компетентності у монологічному мовленні, сформованої на засадах аудіовізуальної імпліцитної професійної орієнтації залишаються поза увагою методистів.

Мета цієї статті полягає у визначенні критеріїв оцінювання рівня іншомовної комунікативної компетентності студентів економічних спеціальностей у монологічному мовленні, сфрормованої на засадах імпліцитної професіоналізації з використанням відеофонограми.

Результати дослідження та їх обговорення. Визначимо набір критеріїв для оцінювання рівня іншомовної соціокультурної і професійно орієнтованої комунікативної компетентності у монологічному мовленні з огляду на специфіку нашого дослідження. 3 урахуванням немовного профрілю студентів, їхнього рівня володіння іноземною мовою і початкового етапу навчання виокремлено такі критерії: 1) відповідність висловлювання комунікативній ситуації (або змісту тексту) у бітах інформації; 2) лексична правильність; 3) правильність озвучування лО; 4) граматична правильність; 5) темп мовлення; 6) обсяг висловлювання.

Головним є критерій відповідності висловлювання комунікативній ситуації (або змісту тексту) у бітах інформації, тому що від змістовності мовлення залежить доцільність використання інших критеріїв. Цей критерій дає можливість оцінити здатність студента реалізувати усномовленнєву комунікацію у монологічній формі відповідно до комунікативного завдання. Відповідність висловлювання комунікативній ситуації вимірюється кількістю вико- 
ристаних студентами у мовленні біт інформації - умовних одиниць змісту висловлювання, що відповідають тематичним компонентам запропонованої комунікативної ситуації. Наприклад, тематичними компонентами, необхідними для опису ситуації «Обмін валют», яка належить до відібраних нами для оцінювання рівня іншомовної комунікативної компетентності у монологічному мовленні студентів економічних спеціальностей на початковому етапі навчання, будуть поради щодо місця, де краще здійснити обмін, та інформація про місцезнаходження пункту обміну, курс валют, суму грошей, які необхідно обміняти, і комісійні, які треба сплатити залежно від цієї суми.

Оскільки лексична компетентність $€$ вагомою складовою компетентності студентів економічних спеціальностей у монологічному мовленні, другим значущим критерієм є лексична правильність мовлення. Оцінюючи мовленнєвий продукт, ми спираємося на положення про апроксимовану коректність мовлення, яка $€$ припустимою при комунікативному підході до навчання, й враховуємо передусім помилки, що перешкоджають реалізації комунікативних намірів студентів і, відповідно, досягненню мети спілкування. На лексичному рівні необхідно брати до уваги те, що викривляє зміст висловлювання: 1) вживання однокореневих слів 3 іншим значенням, наприклад: використання ЛО economic adj (економічний) або ЛО economics $n$ (економіка як наука) замість ЛО economy $n$ (економіка як народне господарство); 2) вживання паронімів, наприклад: використання ЛО customer $n$ (споживач) або ЛО custom n (звичай) замість ЛО customs $n$ (митниця); 3) хибний переклад, наприклад: використання ЛО part $n$ (частина) замість ЛО share $n$ (частка); 4) помилки при утворенні похідних слів, наприклад: використання одного з найбільш продуктивних в англійській мові суфіксів -tion замість суфікса -ment для утворення ЛО інвестиція -investition замість investment $n$; 5) вживання родових понять замість видових, наприклад: використання ЛО $\operatorname{tax} n$ (податок) замість ЛО customs duty $n$ (митний збір), використання ЛО transportation $n$ (транспортування) замість ЛО freight $n$ (фрахт - перевезення товарів морськими або повітряними шляхами).

Наступним критерієм, тісно пов'язаним 3 лексичною правильністю висловлювання, є правильність озвучування ЛО. На фонетичному рівні слід брати до уваги: 1) помилки у вимові ключових ЛО, наприклад: вимова слова visa $n$ як ['vaızə] замість ['vı:zə], вимова слова financial adj як [fı'nænf] замість [faı'nænf], вимова слова personnel $n$ (персонал) як слова personal adj (особистий) - ['pз:sənl] замість [.pз:sә'nel]; 2) неправильний наголос, наприклад: вживання слова guarantee $n$ з основним наголосом на першому складі замість останнього, слова textile $n$ з наголосом на другому складі замість першого, слова agriculture $n$ з наголосом на третьому складі замість першого тощо).

Ще одним критерієм, що характеризує відносну правильність мовлення, є граматична правильність. 3 огляду на рівень сформованості граматичної компетентності студентів економічних спеціальностей на I курсі, на граматичному рівні враховуються суттєві помилки, пов'язані із вживанням видо-часових форм дієслова, модальних дієслів, ступенів порівняння прикметників, множини іменників, порядком слів у реченні. Якщо речення містить не більше однієї несуттєвої помилки (наприклад, пропуск артикля або неправильне вживання прийменників), воно розглядається як граматично коректне речення. При цьому в рамках однієї ситуації береться до уваги різноструктурність граматичних конструкцій, тобто у разі вживання однотипних конструкцій бали при повторі не нараховуються.

Наступним критерієм оцінювання $€$ темп мовлення. Визначаючи цей критерій, ми спиралися на результати дослідження В.С.Пащук, яка вимірювала темп мовлення кількістю складів за хвилину: повільний темп - 104 скл./хв., середній темп - 130 скл./ хв., швидкий темп - 161,2 скл./ хв. (Paschuk, 127). Нормальним для студентів I курсу немовних спеціальностей нами вважається темп мовлення, наближений до середнього 115-120 скл./ хв. За темп нижчий за 75 складів за хвилину студент отримує 0 балів.

Обсяг висловлювання визначається за параметрами, запропонованими В.Л. Скалкіним: фрагментарне висловлювання містить 4-6 повних речень, монологічна єдність - 7-12 повних речень (Skalkin, 20). Передбачається, що в рамках кожної із запропонованих ситуацій висловлювання студентів має в середньому складатися з 10 фраз. При оцінці обсягу висловлювання враховується кількість простих і складнопідрядних речень.

Відібрані критерії враховано при розробці завдань зрізів комплексного контролю рівня сформованості іншомовної соціокультурної і професійно орієнтованої комунікативної компетентності у монологічному мовленні студентів економічних спеціальностей на I кур- 
сі. Зрізи комплексного контролю включають 3 завдання. Мета завдань №1 і №2 - оцінити сорормованість іншомовної соціокультурної і профресійно орієнтованої комунікативної компетентності у монологічному мовленні під час спілкування у непрофесійних сфрерах комунікації. Завдання №3 спрямоване на перевірку сформованості вмінь усного перекладу та рівня засвоєння соціокультурно маркованих й економічно маркованих ЛО. Мовлення усіх студентів записується на звуконосії одночасно, а потім прослуховується, аналізується й оцінюється викладачем. Усі завдання студенти виконують усно з голосу викладача.

Для оцінювання рівня іншомовної комунікативної компетентності у монологічному мовленні студентів економічних спеціальностей на початковому етапі навчання, сформованої на засадах аудіовізуальної імпліцитної профресіоналізації, відповідно до Програми 3 англійської мови для професійного спілкування відібрано ситуації: «Відпочинок за системою «Усе включено», «Замовлення квитків», «Прибуття до країни та прикордонно-митні формальності», «Розміщення та мешкання в готелі», «Обмін грошей», «Покупки», «Прокат автомобіля». Виконуючи завдання №1, студент має дати відповіді на 10 спеціальних запитань, тематично пов'язаних з вищезазначеними ситуаціями. Завдання №2 передбачає висловлювання понадфразового рівня у відповідності до чотирьох запропонованих викладачем комунікативних ситуацій. Завдання №3 полягає в усному пофрразовому перекладі аудіотексту, до якого входять 10 тематичних соціокультурно маркованих і 20 тематичних економічно маркованих ЛО, з української на англійську мову.

Представимо критерії оцінювання рівня іншомовної комунікативної компетентності студентів економічних спеціальностей у монологічному мовленні у кожному завданні у балах у вигляді таблиці (Таблиця 1).

Для оцінювання темпу монологічного мовлення у завданнях №1 i №2 застосовано шкалу 1 i шкалу 2 (Таблиці 2 і 3), темп мовлення у завданні №3 оцінювався за шкалою 3 (Таблиця 4).

Таблиця 1.

Критерії оцінювання рівня сформованості іншомовної комунікативної компетентності у монологічному мовленні і вмінь усного перекладу (у балах)

\begin{tabular}{|c|c|c|}
\hline № завдання & Критерії & Максимальна кількість балів \\
\hline $\begin{array}{c}\text { Завдання № } 1 \\
\\
\text { Разом }\end{array}$ & $\begin{array}{l}\text { Відповідність висловлювання комунікативній ситуації } \\
\text { у бітах інформації } \\
\text { Лексична правильність } \\
\text { Правильність озвучування лО } \\
\text { Граматична правильність } \\
\text { Темп мовлення } \\
\text { Обсяг висловлювання }\end{array}$ & $\begin{array}{l}20,00 \\
20,00 \\
20,00 \\
10,00 \\
10,00 \\
20,00 \\
100,00\end{array}$ \\
\hline Завдання № 2 & $\begin{array}{l}\text { Відповідність висловлювання комунікативній ситуації } \\
\text { у бітах інформації, } 4 \text { ситуації } \\
\text { Лексична правильність, максимум } 10 \text { тематичних ло } \\
\text { у кожній з } 4 \text { ситуацій } \\
\text { Правильність озвучування лО, максимум } 10 \text { тема- } \\
\text { тичних ЛО в кожній з } 4 \text { ситуацій } \\
\text { Граматична правильність, } 4 \text { ситуації } \\
\text { Темп мовлення, } 4 \text { ситуації } \\
\text { Обсяг висловлювання, } 4 \text { ситуації }\end{array}$ & $\begin{array}{l}10,00 \text { (за кожну ситуацію) } \\
1,00 \text { (за кожну лО) } \\
\text { 1,00 (за кожну лО) } \\
\text { 5,00 (за кожну ситуацію) } \\
\text { 5,00 (за кожну ситуацію) } \\
\text { 10,00 (за кожну ситуацію) } \\
\text { 200,00 }\end{array}$ \\
\hline Завдання № 3 & $\begin{array}{l}\text { Відповідність висловлювання змісту тексту в бітах } \\
\text { інформації } \\
\text { Лексична правильність } \\
\text { Правильність озвучування ЛО } \\
\text { Граматична правильність } \\
\text { Темп мовлення }\end{array}$ & $\begin{array}{c}20,00 \\
30,00 \\
20,00 \\
10,00 \\
20,00 \\
100,00\end{array}$ \\
\hline
\end{tabular}


Таблиия 2.

Шкала 1

Оцінювання темпу монологічного мовлення у завданні №1 (у балах)

\begin{tabular}{|l|c|c|c|c|c|c|c|c|c|c|}
\hline $\begin{array}{l}\text { Темп } \\
\begin{array}{l}\text { мовлення } \\
\text { (скл./ хв.) }\end{array}\end{array}$ & $\begin{array}{c}75- \\
\text { Кількість }\end{array}$ & $\begin{array}{c}80- \\
84\end{array}$ & $\begin{array}{c}85- \\
89\end{array}$ & $\begin{array}{c}90- \\
94\end{array}$ & $\begin{array}{c}95- \\
99\end{array}$ & $\begin{array}{c}100- \\
104\end{array}$ & $\begin{array}{c}105- \\
109\end{array}$ & $\begin{array}{c}110- \\
114\end{array}$ & $\begin{array}{c}115- \\
119\end{array}$ & $\begin{array}{c}120 \text { i } \\
\text { вище }\end{array}$ \\
\hline \begin{tabular}{l} 
балів \\
\hline
\end{tabular} & 1,00 & 2,00 & 3,00 & 4,00 & 5,00 & 6,00 & 7,00 & 8,00 & 9,00 & 10,00 \\
\hline
\end{tabular}

Таблиия 3.

Шкала 2

Оцінювання темпу монологічного мовлення у завданні №2 (у балах)

\begin{tabular}{|c|c|c|c|c|c|c|c|c|c|c|}
\hline $\begin{array}{l}\text { Темп } \\
\text { мовлення } \\
\text { (скл./ хв.) }\end{array}$ & $\begin{array}{l}75- \\
79\end{array}$ & $\begin{array}{c}80- \\
84\end{array}$ & $\begin{array}{c}85- \\
89\end{array}$ & $\begin{array}{l}90- \\
94\end{array}$ & $\begin{array}{c}95- \\
99\end{array}$ & $\begin{array}{c}100- \\
104\end{array}$ & $\begin{array}{c}105- \\
109\end{array}$ & $\begin{array}{c}110- \\
114\end{array}$ & $\begin{array}{c}115- \\
119\end{array}$ & $\begin{array}{c}120 \text { i } \\
\text { вище }\end{array}$ \\
\hline $\begin{array}{l}\text { Кількість } \\
\text { балів }\end{array}$ & 0,50 & 1,00 & 1,50 & 2,00 & 2,50 & 3,00 & 3,50 & 4,00 & 4,50 & 5,00 \\
\hline
\end{tabular}

Таблиия 4.

\section{Шкала 3}

Оцінювання темпу мовлення в усному перекладі (завдання №3, у балах)

\begin{tabular}{|l|c|c|c|c|c|c|c|c|c|c|}
\hline Темп & $75-$ & $80-$ & $85-$ & $90-$ & $95-$ & $100-$ & $105-$ & $110-$ & $115-$ & $120 \mathrm{i}$ \\
$\begin{array}{l}\text { мовлення } \\
\text { (скл./ хв.) }\end{array}$ & 79 & 84 & 89 & 94 & 99 & 104 & 109 & 114 & 119 \\
\hline $\begin{array}{l}\text { Кількість } \\
\text { балів }\end{array}$ & 2,00 & 4,00 & 6,00 & 8,00 & 10,00 & 12,00 & 14,00 & 16,00 & 18,00 & 20,00 \\
\hline
\end{tabular}

Наведемо приклади завдань та оцінювання мовленнєвого продукту студентів за визначеними критеріями (помилки у висловлюваннях підкреслено).

\section{Завдання 1}

Teacher to Student: You're an exchange student in London University. You're taking part in a public opinion poll. Answer the following questions of the poll agent and record your answers.

Teacher:

1. What functions are performed by travel agencies while arranging tours abroad?

Student: Travel agencies propose vouchers, tickets, reserve rooms, accommodations and propose insurance.

Teacher:

2. What services do your parents spend most money on?

Student: My parents spend most money on bills.

Teacher:

3. Where can you obtain information about exchange rates of foreign currencies to your national currency in Singapore?
Student: _ Exchange rate can be obtained in Singapore in exchange bureaus and banks.

Teacher:

4. What are the advantages and disadvantages of package holidays if compared with holidays on self-catering basis?

Student: Package holidays guarantee good services, meals, accommodation, sometimes extra facilities. And disadvantages of package holidays include _ higher price and maybe that's all.

Teacher:

5. What facilities should a hotel have for you to stay at it?

Student: A hotel should have _ shower in a room.

Teacher:

6. What do holidaymakers buy while travelling over Malaysia?

Student: The most holidaymakers buy handicrafts while travelling over Malaysia.

Teacher:

7. Why do people like buying goods in dutyfree shops? 
Student: Some people buy goods in dutyfree shops because they think their price is lower because they're free of duty.

Teacher:

8. What risks can be covered by insurance?

Student: Insurance can cover personal accidents, medical expenses and loss of personal effects.

Teacher:

9. What are the basic customs regulations when you go from Ukraine to Thailand?

Student: You shouldn't take out from Ukraine explosive, toxic and radioactive substances. And you can take without any duty any items which are included in a duty-free article list and you should pay free on any other articles which you take with you through border.

Teacher:

10. What national and foreign products are among your favourites? Comment on their price and quality.

Student: Digital cameras and various foreign products. Their price is high, but quality is good enough to satisfy my purpose.

Усі висловлювання відповідають ситуації спілкування, тому за кожне 3 них нараховується по 2 бали, що становить разом 20 балів. Лексичні одиниці для оформлення висловлювань 1, 2, 3, 4, 5, 6, 7, 8, 10 відібрано правильно, тому за кожну з цих відповідей нараховується по 2 бали, що становить разом 18 балів. У відповіді на запитання 9 замість економічно маркованої ЛО duty вжито ЛО free (рау free on any other articles), тому за цю відповідь нараховано 1 бал. Загальна кількість балів за лексичну правильність становить 19 балів. Лексичні одиниці у відповідях на запитання 1 , 2, 3, 4, 5, 6, 8, 10 озвучено правильно, тому за кожну з них студент отримує по 2 бали, що дорівнює 16 балам. Лексичні одиниці у відповідях на запитання 7 і 9 озвучено правильно, крім слів lower і toxic, тому за правильність озвучування цих відповідей нараховується по 1 балу. Загальна кількість балів за правильність озвучування становить 18 балів. Відповіді на запитання 2, 3, 4, 5, 6, 7, 8, 9, 10 містять граматично коректні фрази, тому за кожну з них нараховується по 1 балу, не зважаючи на низку помилок, які припускаються під час апроксимованої коректності мовлення (у наведеному прикладі переважно пропуски артиклів). Разом кількість балів за граматичну пра- вильність у цьому завданні становить 8 балів. Темп висловлювання студента наближений до нормального темпу англійського мовлення (122 скл./ хв.), тому за цим показником студент отримує 10 балів. При оцінці обсягу висловлювання враховувалася кількість простих і складнопідрядних речень. Оскільки таких виявилося 13, за обсяг висловлювань у завданні №1 нараховано 13 балів. Разом кількість балів у цьому завданні дорівнює 88 балам з максимальних 100 балів.

\section{Завдання 2}

Розглянемо одну з чотирьох запропонованих студентам комунікативних ситуацій.

Teacher to Student: You're a Ukrainian tourist. You've taken a trip abroad. Share your experience role-playing the following situations typical for everyday life. Do it orally.

Situation 2.

Teacher: You're going to Bali. You have booked a package holiday with the 'Grand Tour' travel agency. Tell your Australian friend who is taking a course of a travel agent about the arrangements the agency has made for you: the air tickets they've reserved, the accommodation they've booked and the travel insurance they've provided. It will add to his/her experience.

Student: _ Travel agency the 'Grand Tour' reserved for me accommodation in Bali. It was single room with _ shower and half board. $\overline{A l s o}$ this agency proposed for me _ insurance which cover medical expenses and _ loss of my personal effects. They reserved for me budget tickets both sides and it was economy class. Also they proposed extra facilities like _ swimming pool and gymnasium. I should pay by credit cards and I used my Visa card and there was no problem on my vacation. _. Hotel seemed to be cheap enough for me and I had the most facilities which I tried to find.

Висловлювання відповідає запропонованій комунікативній ситуації. Студент згадує усі тематичні компоненти, необхідні для ії̈ опису організоване турагенцією місце проживання, замовлення квитків, страховку, додаткові послуги, спосіб оплати - нараховуємо 10 балів. У висловлюванні вжито 22 релевантні тематичні соціокультурно й економічно марковані лексичні одиниці, тому студент отримує максимальні 10 балів за лексичну правильність, не зважаючи на помилку tickets both sides. Наведені ЛО озвучено правильно - нарахо- 
вуємо максимальні 10 балів за правильність озвучування. Ситуація складається з 11 простих і складнопідрядних речень, тому за обсяг висловлювання студент отримує 10 балів. 2 речення містять суттєві граматичні помилки ( в одному із складнопідрядних речень не узгоджено минулий і теперішній час і неправильно обрано модальне дієслово), тому за граматичну правильність нараховуємо 3 бали з 5 можливих балів. Темп висловлювання наближений до нормального темпу англійського мовлення (120 скл./ хв.) - нараховуємо 5 балів. Разом кількість балів за цю ситуацію дорівнює 48 балам з 50 можливих балів.

Завдання 3

Teacher to Student: Your Ukrainian friend asks you to help him translate a short review about package holidays which he intends to publish on his blog site. Give him a hand by conveying in English the meaning of some phrases you'll hear in Ukrainian over the phone. Do it orally.

Teacher: Готель «Шангрі-Ла» (1), розташований серед мальовничих садів Сінгапура (2), нагадує заміський курорт (3). «Шангрі-Ла» пропонує (4) широкий спектр послуг (5): ресторани, магазини (6), басейни, спортивні майданчики (7). Персонал готелю (8) дбає про високі стандарти (9) обслуговування клієнтів (10). 750 (11) просторих кімнат на двох (12) і номерів люкс (13) приваблюють своїм затишком (14) як відпочиваючих (15), так і бізнесменів (16). Готель має можливості (17) для проведення переговорів (18), конференцій і презентацій (19). «Шангрі-Ла» користується великою популярністю (20), тому номери у готелі (21) необхідно замовляти заздалегідь (22). Щоправда (23), родині Кравченків, яка давно мріяла про подорож до Сінгапура (24), путівки до «Шангрі-Ла» (25) запропонували купити у турагенстві (26). Можливість подорожувати (27), проживати і харчуватися в готелі (28) за встановлену ціну без доплат (29) надає відпочинок за системою «Усе включено» (30). Тому родина Кравченків обрала (31) саме такий відпочинок (32). Крім путівок, авіабілетів і віз (33) родина отримала страховку (34), яка була дійсна (35) на весь час їхнього перебування закордоном (36). Страховка передбачала медичні та інші витрати (37), такі як покриття ризику на випадок скасування замовлення (38). Турагенство надало родині групову знижку (39) і бланки для оформлення рекламацій (40).

Student: _ Hotel Shangri-La located among picturesque gardens of Singapore looks like a resort. Shangri-La proposes _ range of services: restaurants, stores, swimming pools, gymnasiums. __ Personnel of Shangri-La hotel proposes high standards of client service. 750 spacious double rooms and suit rooms attract by their comfort both holidaymakers and businessmen. Hotel has facilities for carrying out negotiations, conferences and presentations. Shangri-La is very popular, that's why apartments should be booked in advance. Although Kravchenko family which dreamt about travel to Singapore should be proposed to buy vouchers to Shangri-La at _ travel agency. Opportunity to travel, stay and eat at _ hotel without extras for __ fixed price is guaranteed by 'all inclusive'. That's why _ Kravchenkos chose exactly this type of holidays. In addition to vouchers, air tickets and visas _ family was insured. It was valid during all their period of staying abroad. The insurance covered medical and other expenses such as cancellation fee.

Travel agency gave the family a group discount and reclamation forms.

3 метою оцінювання відповідності змісту перекладеного тексту тексту-оригіналу виділяємо в українському тексті біти інформації (у наведеному прикладі їх умовно позначено цифрами у дужках), за кожен з яких нараховуємо по 0,5 бала. У перекладі згадано усі біти інформації, тому студент отримує 20 балів за відповідність перекладу змісту тексту українською мовою. Під час перекладу вжито релевантні еквіваленти 27 тематичних лексичних одиниць (у тексті-оригіналі соціокультурно марковані ЛО виділено курсивом, економічно марковані лО підкреслено) - нараховуємо 27 балів за лексичну правильність. 320 економічно маркованих лексичних одиниць правильно озвучено 19, тому правильність озвучування дорівнює 19 балам. Під час перекладу вжито коректно 8 з 10 відібраних граматичних структур - Present Simple Active - речення 1, 4; Present Simple Active від дієслова 'to be' речення 6; Modal Verbs - речення 6; Present Simple Passive - речення 8; Past Simple Active - речення 9, 12; Past Simple Active від дієслова 'to be' - речення 11, тому за грама- 
тичну правильність нараховуємо 8 балів. Темп мовлення студента складав 118 скл./ хв., тому за цим показником студент отримує 18 балів. Загальна сума балів за вміння усного перекладу в цьому завданні становить 92 бали з максимальних 100 балів.

Висновки. Оцінювання рівня іншомовної соціокультурної і професійно орієнтованої комунікативної компетентності у монологічному мовленні студентів економічних спеціальностей на початковому етапі навчання за вищевизначеними критеріями доводить доцільність іï формування на засадах аудіовізуальної імпліцитної професійної орієнтації. Для підвищення змістовності мовлення та відповідності висловлювань студентів комунікативній ситуації суттєво, що відеофонограма, на відміну від друкованих матеріалів, актуалізує інтегровану інформацію про усі компоненти ситуації: обставини, місце і час спілкування; мовця, його партнерів по спілкуванню та соціальні відносини між комунікантами; лінгвістичні особливості висловлювання; комунікативну мету і наміри мовців.

На підвищення змістовності мовлення також впливає кількість та якість засвоєних і вжитих у висловлюваннях студентів соціокультурно й економічно маркованих лексичних одиниць. Аудіовізуальна імпліцитна професійна орієнтація значно поповнює лексичний запас студентів-першокурсників під час організації спілкування в непрофесійних сфрерах і прискорює формування іншомовної комунікативної компетентності на подальших етапах навчання. Покращення якісних показників правильності озвучування соціокультурно й економічно маркованих ЛО пов'язано з тим, що відеофонограма надає зразки озвучування, забезпечуючи пріоритет слухових сигналів мовлення та можливість нормативного засвоєння лексичних одиниць саме у звуковій формі.

\section{References}

Asadchykh, O. V. (2007). Metodyka Navchannia Studentiv Movnykh Spetsialnostei Usnoho Yaponskoho Monolohichnoho Movlennia na Pochatkovomu Etapi (Methodology of Teaching Linguistic Students Oral Speech Production in Japanese at the Primary Stage of Education). Diss.
Taras Shevchenko National University of Kyiv, Print.

Bakayeva, G. and Borysenko, O. (2005). Programa z Angliyskoyi Movy dlia Profesiynoho Spilkuvannia (English for Specific Purposes. National Curriculum for Universities). Kyiv: Lenvit, Print.

Fedorova, I. A. (2006). Navchannia Maibutnikh Ekonomistiv-Mizhnarodnykiv Profesiyno Spriamovanoho Anglomovnoho Monolohu-Povidomlennia (Teaching Future International Economists Profession Oriented English Monologue Message). Diss. Kyiv National Linguistic University. Print.

Liamzina, N. K. (2015). Metodyka Navchannia Maibutnikh Ekonomistiv Profesiyno Orientovanoho Angliyskoho Monolohichnoho Movlennia z Vykorystanniam Informatsiyno-Komunikatsiynykh Tekhnolohiy (Methodology of Teaching Future Economists Profession Oriented English Oral Speech Production with Information and Communication Technologies). Diss. Kostiantyn Ushinskyi National Pedagogic University of Southern Ukraine. Print.

Kirzhner, S. E. (2009). Navchannia Maibutnikh Yurystiv Usnoho Profesiyno Spriamovanoho Angliyskoho Monolohichnoho Movlennia z Vykorystanniam Avtentychnoyi Videofonogramy (Teaching Future Lawyers Profession Oriented English Oral Speech Production with Authentic Video). Diss. Kyiv National Linguistic University. Print.

Miroshnichenko, E. V. (1996). Obuchenie Professionalnoy Leksike Studentov-Ekonomistov pri Ustnorechevom obshchenii $v$ Neprofessionalnykh Sferakh Kommunikatsyi (Teaching Students of Economics Professional Terminology in Non-professional Spheres of Oral Communicaion). Diss. Kyiv National Linguistic University. Print.

Paschuk, V. S. (2002). Navchannia Studentiv Movnykh Spetsialnostei Usnoho Angliyskoho Monolohichnoho Movlennia z Vykorystanniam Avtentychnykh Khudozhnikh Filmiv (Teaching Linguistic Students English Oral Speech Production with Authentic Feature Films). Diss. Kyiv National Linguistic University. Print.

Skalkin, V. (1983). Obuchenie Monologicheskomu Vyskazyvaniyu (Teaching Oral Speech Production). Kyiv: Rad. Shkola. Print. 


\title{
CRITERIA TO ASSESS COMMUNICATIVE FL COMPETENCE IN MONOLOGUE PRODUCTION OF ECONOMICS MAJORS IN THE PROCESS OF AUDIOVISUAL IMPLICIT SPECIALIZATION
}

\author{
Nataliia Lutkovska \\ Foreign Languages for Natural Sciences Department, Institute of Philology, Taras Shevchenko National University of Kyiv,
} Ukraine

Abstract.

Background: Professionally oriented training implies involvement of professional knowledge and job-related skills. However, non-linguistics majors at the primary stage of tertiary education have no experience in specialism-related areas and situations. As a result, they fail to communicate effectively in the professional environment. To solve the problem, E. Miroshnichenko has introduced 'implicit specialization', i.e. integrated development of socio-cultural and professionally oriented communicative FL competence in non-professional communication spheres. The researcher implements her teaching strategy based on printed materials, whereas the author of this paper advocates a somewhat different approach: communicative competence in English can be acquired through audiovisual implicit specializing.

Purpose. The assessment system is an integral and essential part of teaching and learning. It should provide valid and reliable measures for evaluating communicative FL competence. The purpose of our research is to develop assessment criteria for measuring the development of communicative FL competence in monologue production in the process of audiovisual implicit specializing of would-be economists.

Results. Given non-linguistics specialization of students, their FL proficiency level and primary stage of tertiary education, we offer the following criteria to assess communicative FL competence:

1) relevance of a monologue to the communicative situation;

2) accuracy and appropriateness of vocabulary;

3) pronunciation accuracy;

4) grammar accuracy and range of grammatical structures;

5) speech tempo;

6) number of simple and compound sentences in the utterance.

In the context of communicative approach, when assessing accuracy and appropriateness of language use, it is essential to take notice only of those lexical, grammatical and phonetic mistakes that distort the meaning and interfere with students' ability to produce comprehensible utterances. To illustrate the assessment procedure, the article provides some assignments and samples of students' answers.

Discussion. Application of the above-mentioned criteria to assess socio-cultural and professionally oriented communicative FL competence in monologue production of Economics majors verifies practicability of communicative FL competence development based on audiovisual implicit specializistion. Situational models of communication incorporating lexical units of economic register in non-professional communication presented in videos are of primary importance for successful development of lexical competence both at the primary and follow-up stages of tertiary education. Pronunciation standards provided by video facilitate the qualitative upgrading of pronunciation skills.

Key words: audiovisual implicit specialization, video, socio-cultural and professionally oriented communicative foreign language competence, assessment criteria, monologue production, lexical units of socio-cultural and economic registers, students majoring in Economics.

Vitae:

Lutkovska Nataliia is an Assistant Professor of Foreign Languages for Natural Sciences Department within the Institute of Philology, Taras Shevchenko National University of Kyiv. Her areas of research interests include implicit specializing, teaching non-linguistic students through video, role-playing activities.

Correspondence: natalia.ska@gmail.com IPИНА КОСТЕНКО (м. КИїв)

УДК 371.15:81'243

ORCID: 0000-0003-3997-2205

ORCID: 0000-0003-2400-8990

\section{ІНТЕРАКТИВНИЙ СПЕЦКУРС «ІНОЗЕМНА МОВА ПРОФІЛЬНОГО СПРЯМУВАННЯ» ДЛЯ МАЙБУТНІХ УЧИТЕЛІВ ІНОЗЕМНОЇ МОВИ ЗАГАЛЬНООСВІТНІХ ПРОФІЛЬНИХ ШКІЛ III СТУПЕНЯ: ЗМІСТ ТА МЕТОДИКА ВИКЛАДАННЯ}

\footnotetext{
Розглянуто особливості змісту інтерактивного спеціалізованого курсу «Іноземна мова профрільного спрямування» для майбутніх учителів іноземної мови загальноосвітніх профрільних шкіл III ступеня як засіб теоретичної і практичної підготовки майбутніх учителів, що спряє їхньому особистісному і профресійному розвитку. Пропонується опис дисципліни, їі основні завдання, а також короткий огляд лекційних і практичних занять, що складають зміст спецкурсу.
}

Ключові слова: майбутні вчителі, професійна іншомовна компетентність, комунікативні стратедії, професійне іншомовне спілкування. 